\title{
Metformin suppresses hypoxia-induced stabilization of HIF-1 through reprogramming of oxygen metabolism in hepatocellular carcinoma
}

\author{
Xinke Zhou ${ }^{1, *}$, Jitao Chen ${ }^{1,2, *}$, Gao Yij, ${ }^{1, *}$ Min Deng ${ }^{2}$, Hao Liu ${ }^{2}$, Min Liang ${ }^{1}$, Boyun \\ $\mathrm{Shi}^{1}$, Xin $\mathrm{Fu}^{3}$, Yuqin Chen ${ }^{3}$, Liangcai Chen ${ }^{1,2}$, Zhimin $\mathrm{He}^{2}$, Jian Wang ${ }^{3}$, Jifang Liu ${ }^{1,2}$ \\ ${ }^{1}$ Department of Respiratory Medicine and Cancer Center, The 5th Affiliated Hospital of Guangzhou Medical University, \\ Guangzhou, PR China \\ ${ }^{2}$ Cancer Hospital and Cancer Research Institute, Guangzhou Medical University, Guangzhou, PR China \\ ${ }^{3}$ State Key Laboratory of Respiratory Disease, The 1st Affiliated Hospital of Guangzhou Medical University, Guangzhou, \\ PR China \\ *These authors have contributed equally to this work
}

Correspondence to: Jian Wang, e-mail: jianwang1986@yahoo.com

Jifang Liu, e-mail: yzhbb2012@126.com

Keywords: HIF-1a, metformin, metabolic reprogramming, hypoxia, hepatocellular carcinoma

Received: June 28, $2015 \quad$ Accepted: November 16, $2015 \quad$ Published: November 28, 2015

\section{ABSTRACT}

Overexpression of hypoxia-induced factor 1 (HIF-1) has been shown to be involved in the development and progression of hepatocellular carcinoma (HCC). HIF-1 should therefore be a promising molecular target for the development of anti-HCC agents. Metformin, an established antidiabetic drug, has proved to also be effective in treating cancer although the precise underlying mechanisms of this activity are not fully elucidated. The aim of this study was to investigate the effects of metformin on the expression of HIF-1 and oxygen metabolism in HCC. The results showed that metformin inhibited hypoxia-induced HIF-1 accumulation and activation independent of AMP-activated protein kinase (AMPK). Moreover, this decrease in HIF1 accumulation was accompanied by promotion of HIF-1 protein degradation. In addition, metformin significantly decreased oxygen consumption, ultimately leading to increased intracellular oxygen tension and decreased staining with the hypoxia marker pimonidazole. In vivo studies demonstrated that metformin delayed tumor growth and attenuated the expression of HIF-1 in HCC tumor xenografts. Together, these findings suggest that metformin decreases hypoxia-induced HIF-1 accumulation by actively suppressing mitochondrial oxygen consumption and enhancing cellular oxygenation ability, providing a fundamental mechanism of metformin activity against HCC.

\section{INTRODUCTION}

Hepatocellular carcinoma (HCC) is one of the most prevalent fatal cancers worldwide and the second leading cause of death in China. Multiple environmental and genetic risk factors are associated with the high incidence of HCC development and progression and unsatisfactory mortality rate. Thus, a better understanding of the molecular mechanisms governing hepatocarcinogenesis and $\mathrm{HCC}$ progression will contribute to identification of new therapeutic strategies for this highly malignant tumor.

Increasing evidence suggests that intratumor hypoxia is a common phenomenon of solid tumors, including $\mathrm{HCC}$, and an important microenvironmental factor influencing development of a malignant phenotype [1]. Hypoxia-inducible factor 1 (HIF-1), a heterodimer consisting of $\alpha$ and $\beta$ subunits, is a key transcription factor regulating the cellular response to hypoxia [2]. HIF- $1 \alpha$ has been found to be upregulated in a variety of human malignancies, leading to an increased capacity for metastasis and an unfavorable prognosis [3, 4]. Whereas HIF- $1 \beta$ is a constitutive nuclear protein, HIF- $1 \alpha$ is tightly regulated according to oxygen availability through its protein stability. In the presence of abundant oxygen, HIF$1 \alpha$ is rapidly degraded by polyubiquitination via the VonHippel-Lindau tumor suppressor protein and subsequent 
proteasomal degradation [5]. Under hypoxic conditions, HIF- $1 \alpha$ is stabilized and translocates to the nucleus, where it dimerizes with HIF- $1 \beta$ and activates the expression of a broad range of target genes including glucose transporter 1 (Glut1) and carbonic anhydrase IX (CAIX), facilitating tumorigenesis and cancer progression [6-8].

Metformin, a commonly prescribed biguanide, has been used as a first-line treatment for type II diabetes for over 50 years. It efficiently and safely lowers blood glucose levels without serious side effects [9, 10]. Recently, increasing lines of epidemiologic evidence have revealed that diabetic patients who are treated with metformin have reduced cancer incidence and mortality $[11,12]$. In addition, a great number of in vitro and in vivo studies have revealed a direct action of metformin on many types of cancer cell, including HCC [13-15]. Metformin may therefore be a potential therapeutic agent for the treatment of HCC, although its mechanism of anticancer action remains unclear. Recently, several studies have demonstrated that metformin inhibits HIF$1 \alpha$ expression in patients with breast cancer [16] or hepatocellular carcinoma Bel-7402/5-fluorouracil (Bel$\mathrm{Fu}$ ) cells [17]. However, the mechanism of such regulation remains to be elucidated. Moreover, metformin has been found to activate AMP-activated protein kinase (AMPK), a major sensor of the energetic status of the cell [18], via a mechanism dependent on liver kinase B1 (LKB1) [19, 20]. The LKB1-AMPK-mammalian target of rapamycin (mTOR) pathway is a key moderator of HIF-1-targeted genes and HIF-1-mediated cellular metabolism [21]. Therefore, we questioned whether metformin, which is a known AMPK activator, regulates the expression of HIF-1 $\alpha$ protein in HCC cells. The present study aims to explore the effect of metformin on HIF-1 $\alpha$ expression and activation in $\mathrm{HCC}$ cells and xenografts.

\section{RESULTS}

\section{Metformin represses hypoxia-induced accumulation of $\mathrm{HIF}-1 \alpha$ protein in hepatoma cells}

To examine the effect of metformin on HIF$1 \alpha$ protein content, time-course and dose-response experiments were conducted to determine alterations in HIF-1 $\alpha$ protein in the presence of metformin. As expected, $\mathrm{HIF}-1 \alpha$ protein was undetectable in $\mathrm{HepG}_{2}$ cells under normoxia, but its expression markedly increased under hypoxia. In the presence of metformin, HIF-1 $\alpha$ protein content was dramatically diminished and this decrease persisted as long as the drug was present for at least up to $24 \mathrm{~h}$ under hypoxic conditions (Figure 1a). Dose-response experiments demonstrated that metformin attenuated hypoxia-induced HIF-1 $\alpha$ protein expression in $\mathrm{HepG}_{2}$ cells in a dose-dependent manner, with complete abrogation at $10 \mathrm{mmol} / \mathrm{L}$ (Figure 1b). Further confirming the effect of metformin, the accumulation of HIF-1 $\alpha$ was also diminished in another HCC cell line, Huh7, by treatment with metformin at a concentration of $1 \mathrm{mmol} / \mathrm{L}$ (Figure $1 \mathrm{c}$ and $1 \mathrm{~d}$ ). In addition, $\mathrm{CoCl}_{2}$, a hypoxia-mimicking reagent, induced accumulation of HIF-1 $\alpha$ and this increase could also be decreased by metformin (Figure 1e). In contrast, $H I F-1 \alpha$ mRNA levels were not reduced by metformin under hypoxic conditions (Figure 1f), suggesting that metformin decreased HIF-1 $\alpha$ protein expression via posttranslational mechanisms.

\section{Metformin inhibits hypoxia-induced HIF-1a transactivation activity}

To further determine whether metformin-mediated inhibition of HIF-1 $\alpha$ protein expression leads to functional suppression of HIF-1 $\alpha$, we measured the transcriptional activity of HIF-1 $\alpha$ in $\mathrm{HepG}_{2}$ cells transiently transfected with HIF-1 $\alpha$ reporter vector and pEGFP-C2. As shown in Figure 2a, hypoxic stress increased luciferase activity up to 17-fold compared with the normoxic condition, whereas metformin significantly inhibited hypoxia-induced luciferase activity by $52.9 \%$. We next verified whether inhibition of HIF-1 $\alpha$ alters the transcriptional activation of HIF- $1 \alpha$ target genes. Pretreatment with $1 \mathrm{mmol} / \mathrm{L}$ metformin significantly reduced the hypoxic induction of specific HIF-1 $\alpha$ downstream genes CAIX and Glut1, as measured by quantitative RT-PCR (Figure 2b). These results were confirmed in Huh7 cells, which also showed a significant decrease in HIF-1 $\alpha$ transactivation activity after metformin treatment (Figure S1).

\section{Metformin suppresses hypoxia-induced HIF-1a expression independent of AMPK}

Numerous reports have shown that metformin inhibits tumorigenesis in a manner dependent on AMPK $[22,23]$. To investigate the effect of AMPK on the inhibitory activity of metformin on hypoxia-induced HIF$1 \alpha$ protein accumulation, we took a genetic or chemical approach to inhibit AMPK activity under hypoxic conditions. As shown in Figure 3, decreasing the level of AMPK $\alpha$ protein using specific siRNA or AMPK inhibitor did not affect hypoxia-induced HIF-1 $\alpha$ expression and failed to restore the inhibitory effects of metformin on hypoxia-induced HIF-1 $\alpha$ expression in both $\mathrm{HepG}_{2}$ and Huh7 cell lines, implying that metformin inhibited hypoxiainduced HIF-1 $\alpha$ protein expression independent of AMPK.

\section{Metformin promotes protein degradation of HIF-1 $\alpha$}

In general, the accumulation of HIF-1 $\alpha$ is dependent on the balance between its protein synthesis and degradation. HIF-1 $\alpha$ is degraded mainly through the ubiquitin-proteasome pathway $[24,25]$. To investigate the 
involvement of proteasomal degradation in metformintreated cells, we treated $\mathrm{HepG}_{2}$ and Huh7 cells with MG132 (a proteasomal inhibitor) for $4 \mathrm{~h}$, followed by co-incubation with metformin for $4 \mathrm{~h}$ in hypoxic conditions. As shown in Figure 4a, MG-132 restored the inhibitory effect of metformin on hypoxia-induced HIF$1 \alpha$ accumulation. To further confirm the involvement of metformin in the degradation of HIF-1 $\alpha$, the half-life of HIF-1 $\alpha$ was examined in normoxia with or without metformin treatment. $\mathrm{HepG}_{2}$ and $\mathrm{Huh} 7$ cells were pretreated in hypoxia for $4 \mathrm{~h}$ and then co-incubated with cycloheximide (CHX, a global protein synthesis inhibitor) and metformin for 0, 15, 30, and 60 min under normoxic conditions. These results demonstrated that the protein degradation rate of HIF-1 $\alpha$ was not significantly altered in metformin-treated and control cells at $15 \mathrm{~min}$ whereas HIF-1 $\alpha$ protein was completely degraded in the metformin-treated cells at $30 \mathrm{~min}$, in sharp contrast to HIF-1 $\alpha$ in the control cells (Figure 4b). Collectively, these data show that the inhibitory effect of metformin on HIF- $1 \alpha$ accumulation is mediated by an increase in protein degradation.

\section{Decreased oxygen consumption correlates with degradation of HIF-1 $\alpha$ protein in metformin- treated cells}

In earlier work, we found that a low dose of metformin decreased mitochondrial respiratory chain complex I activity, leading to depletion of intracellular ATP levels [26]. To address the underlying mechanisms responsible for the metformin-mediated increase in HIF-1 $\alpha$ protein degradation, we investigated the effect of metformin on mitochondrial biogenesis,

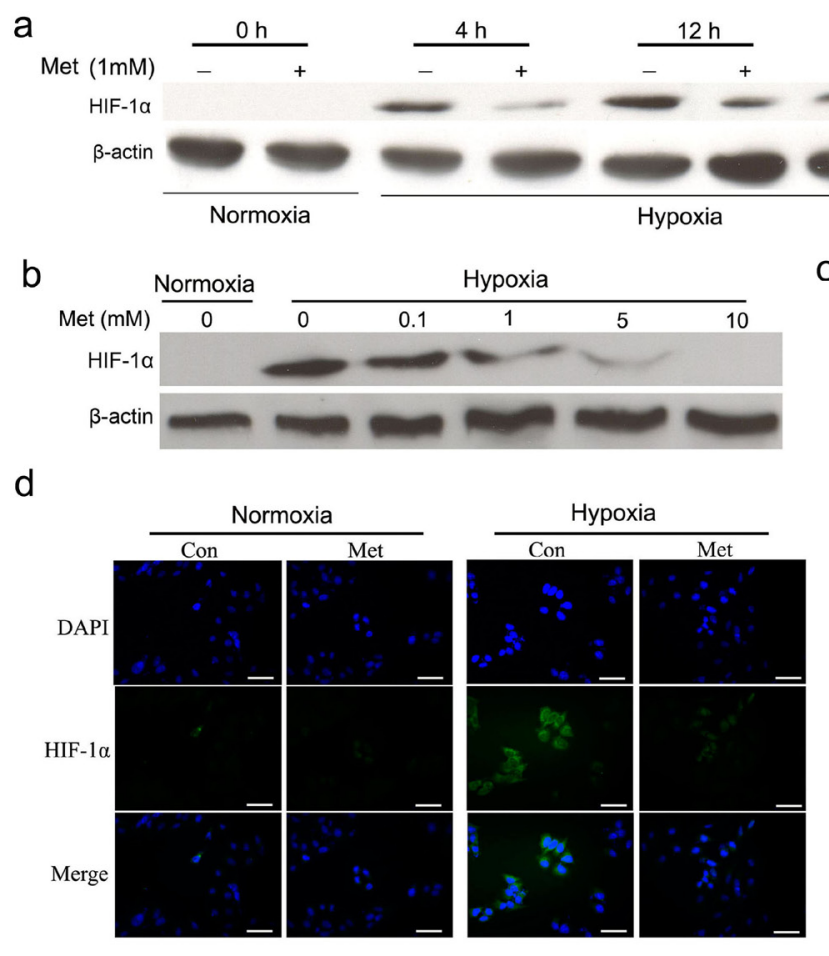

e

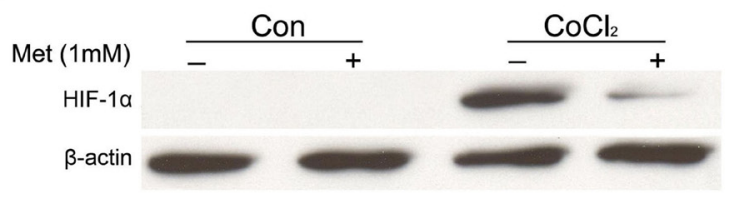

C

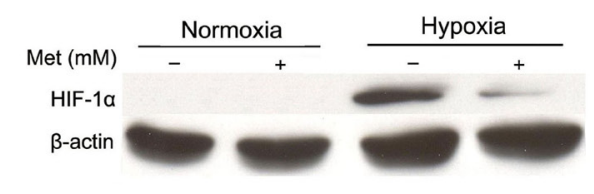

$f$

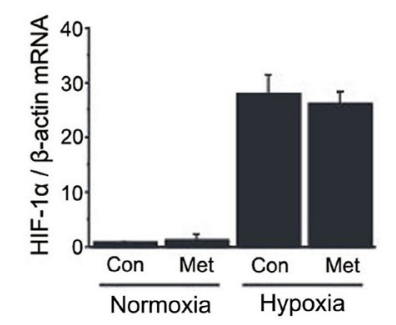

Figure 1: Metformin decreases HIF-1 $\alpha$ protein levels in $\mathbf{H C C}$ cells. a. and $\mathbf{b}$. Western blot analysis of HIF-1 $\alpha$ protein in $\mathrm{HepG}_{2}$ cells treated for different times or with various concentrations of metformin as indicated under normoxia or hypoxia. c. and d. Expression of HIF-1 $\alpha$ protein was detected using western blot and immunofluorescence analysis, respectively, in Huh7 cells with or without metformin treatment under normoxic or hypoxic conditions. Scale bars: $50 \mu \mathrm{m}$. e. $\mathrm{HepG}_{2}$ cells were pretreated with $100 \mu \mathrm{mol} / \mathrm{L} \mathrm{CoCl}$ for $3 \mathrm{~h} \mathrm{before}$ incubation with $1 \mathrm{mmol} / \mathrm{L}$ metformin for $12 \mathrm{~h}$ and the protein expression of HIF- $1 \alpha$ was assayed by western blotting. f. Relative expression of $H I F-1 \alpha$ mRNA was examined by real-time RT-PCR in $\mathrm{HepG}_{2}$ cells in the presence or absence of metformin. $\beta$-actin was used as the internal loading control. Con, control; Met, metformin. 
mitochondrial respiratory chain complex I activity, oxygen consumption, and reactive oxygen species (ROS) production. As shown in Figure $5 \mathrm{a}$ and $5 \mathrm{~b}$, metformin had no significant effect on mitochondrial morphology and number in $\mathrm{HepG}_{2}$ cells compared with controls under hypoxic conditions. In accordance with our previous study [26], metformin significantly inhibited complex I activity in hypoxia (Figure 5c). Oxygen consumption was also measured in $\mathrm{HepG}_{2}$ cells treated with $1 \mathrm{mmol} / \mathrm{L}$ metformin under normoxic and hypoxic conditions for $4 \mathrm{~h}$. As shown in Figure 5d, hypoxia decreased oxygen consumption to $71.7 \%$ that of the control in normoxia, which was similar to the results of the previous study [27]. Of note, metformin significantly blunted oxygen consumption compared with control cells under hypoxic conditions. To further explore whether ROS production is implicated in the inhibitory effects of metformin on HIF-1 $\alpha$ expression, we examined DHE staining, which produces a red fluorescence in a typically nuclear localization when oxidized to ethidium bromide by $\mathrm{O}_{2}$, in $\mathrm{HepG}_{2}$ cells. As shown in Figure 5e, hypoxia decreased DHE-associated fluorescence compared with normoxic conditions. However, metformin increased DHE staining independent of oxygen tension, as reported by Anedda et al. [28], suggesting that intracellular ROS production was not involved in the inhibitory effect of metformin on HIF-1 $\alpha$ expression. Intriguingly, treatment of $\mathrm{HepG}_{2}$ cells with metformin significantly attenuated the intensity of pimonidazole staining (a hypoxiasensitive marker), suggesting that metformin rescues the hypoxic state and increases intracellular oxygen tension under hypoxic conditions (Figure 5f). Additionally, hypoxia appeared to induce nuclear expression of HIF$1 \alpha$ compared with normoxic conditions, and metformin inhibited hypoxia-induced HIF-1 $\alpha$ nuclear staining (Figure 5f). Similarly, cellular oxygen consumption was significantly lower in metformin-treated Huh7 cells than in control cells (Figure S2). Taken together, these results indicate that downregulation of cellular oxygen consumption via the induction of mitochondrial respiration dysfunction by metformin at least partially contributes to the $\mathrm{O}_{2}$-dependent degradation of HIF-1 $\alpha$.

\section{Metformin decreases HIF-1 $\alpha$ expression in HCC xenografts}

To further investigate the effect of metformin on the expression of HIF-1 $\alpha$ in vivo, we treated nude mice bearing HCC xenografts with $250 \mathrm{mg} / \mathrm{kg}$ body weight of metformin for 35 days. As expected, treatment of subcutaneously implanted $\mathrm{HepG}_{2}$ cell tumor xenografts with metformin obviously prevented tumor growth and proliferation, as measured by Ki67 expression (Figure 6 and Figure S3). As shown in Figure 6a, mice treated with metformin exhibited smaller tumors in the $\mathrm{HepG}_{2}$ xenograft compared with vehicle-treated control mice. Measurement of tumors every $5 \mathrm{~d}$ showed that tumor growth was dramatically reduced in metformin-treated mice (Figure 6b). In line with these results, tumor weight

a

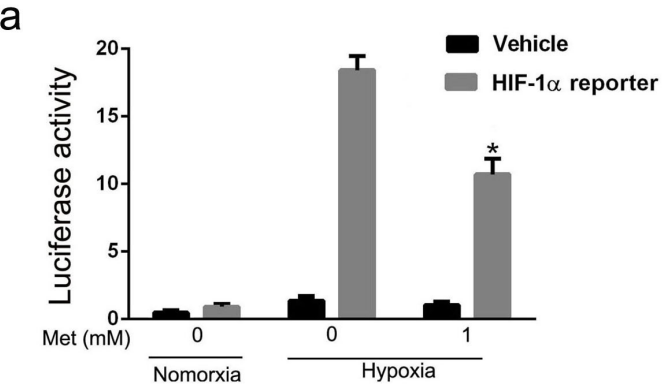

b
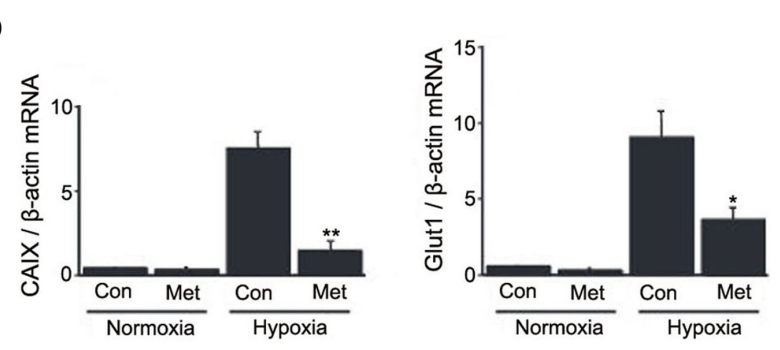

Figure 2: Effect of metformin on transactivation activity of HIF-1 $\alpha$ in HepG2 cells. a. Luciferase activity was measured in $\mathrm{HepG}_{2}$ cells that were transiently transfected with a HIF-1 $\alpha$ reporter gene and then treated with $1 \mathrm{mmol} / \mathrm{L}$ metformin for $12 \mathrm{~h}$ under normoxic or hypoxic conditions. ${ }^{*} P<0.05$ compared with cells transfected with HIF-1 $\alpha$ reporter without metformin treatment in hypoxia. b. Real-time RT-PCR analyses of CAIX and Glut1 mRNA expression in $\mathrm{HepG}_{2}$ cells with or without metformin treatment under normoxic and hypoxic conditions. The relative amounts of $C A I X$ and Glut 1 mRNA were normalized to $\beta$-actin expression. Hypoxia significantly induced CAIX and Glut-1 mRNA expression in $\mathrm{HepG}_{2}$ cells, and $1 \mathrm{mmol} / \mathrm{L}$ metformin inhibited the induction of these $\mathrm{mRNAs}$ in hypoxia. $*, P<0.05$; ** $P<0.01$ compared with control under hypoxic conditions. All experiments were performed three times. Data shown represent the means $\pm \mathrm{SD}$. Con, control; Met, metformin. 
at the end of the study was significantly diminished by metformin treatment (Figure 6c). A remarkable reduction in the protein levels of HIF-1 $\alpha$, Glut1, and CAIX was also observed in immunohistochemical analysis of sections of tumor tissue from mice treated with metformin (Figure $6 \mathrm{~d}$ and 6e). These results confirmed that downregulation of HIF-1 $\alpha$ by metformin significantly contributes to the inhibition of tumor growth in HCC xenografts.

\section{DISCUSSION}

In this study, we showed that metformin decreases hypoxia-induced HIF-1 $\alpha$ protein content by promoting protein degradation rather than through reduction of protein synthesis or mRNA transcription. Suppression of mitochondrial oxygen consumption by metformin was found to be involved in the degradation of HIF$1 \alpha$. Furthermore, metformin decreased the expression of HIF-1 $\alpha$ in HCC xenografts. These results reveal a

a
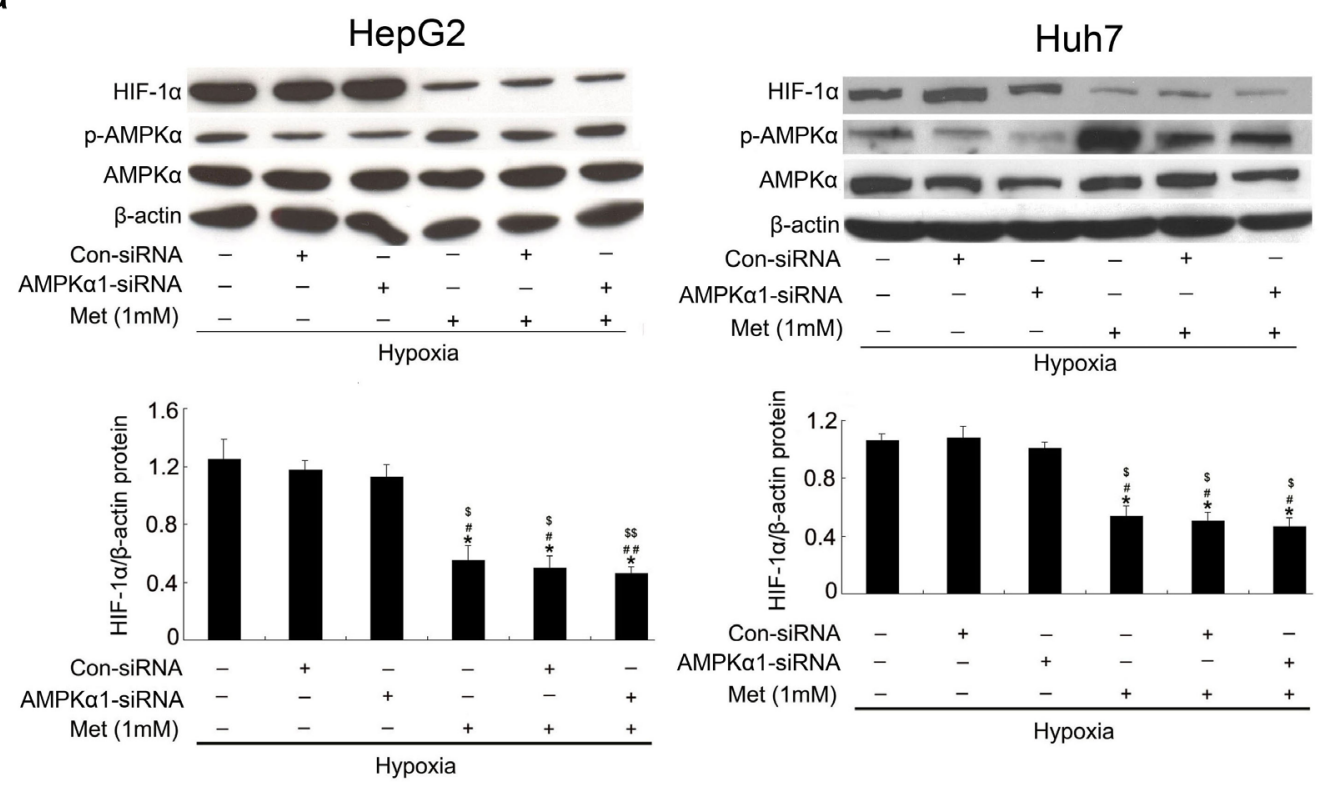

b
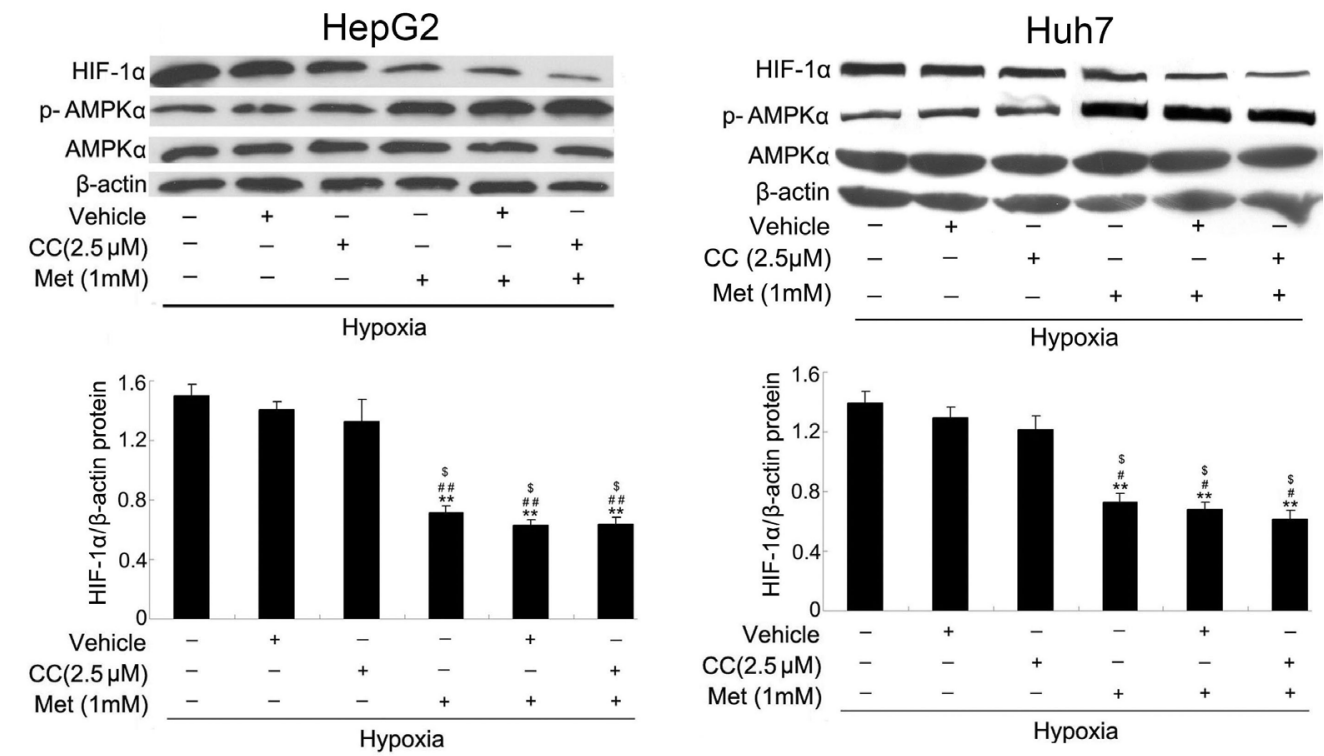

Figure 3: Metformin suppresses HIF-1 $\alpha$ protein levels independent of AMPK. a. and b. Western blot analyses of HIF-1 $\alpha$, AMPK $\alpha$, and phosphorylated form of AMPK $\alpha(\mathrm{p}-\mathrm{AMPK} \alpha)$. HepG $\mathrm{F}_{2}$ and Huh7 cells were transiently transfected with AMPK $\alpha 1$ siRNA or treated with Compound C (CC; AMPK inhibitor), and then incubated with $1 \mathrm{mmol} / \mathrm{L}$ metformin for $12 \mathrm{~h}$ under hypoxic conditions before immunoblotting with specific antibodies as indicated. $\beta$-actin was used as the internal loading control. *, $P<0.05$; **, $P<0.01$ vs. untreated cells; \#, $P<0.05$; \#\#, $P<0.01$ vs. control siRNA-transfected or vehicle-treated cells; $\$, P<0.05 ; \$ \$, P<0.01$ vs. AMPK $\alpha 1$-siRNA or CCtreated cells. Results from three independent experiments are shown. 
mechanism by which metformin downregulates HIF-1 $\alpha$ in HCC cells.

Like other solid tumors, HCC tumors have large hypoxic regions and hypoxia is an important microenvironmental factor in promoting HCC progression and metastasis. Adaptation of tumor cells to hypoxia is mainly regulated by HIF-1 $\alpha$, which has been reported to be upregulated in HCC [1]. Interestingly, Ling et al. [17] found that metformin treatment led to decreased HIF-1 $\alpha$ expression in Bel-Fu cells, which was consistent with the previous observation that metformin therapy reduced serum levels of HIF-1 $\alpha$ in patients with breast cancer [16]. Suppression of HIF-1 $\alpha$ expression would open a new perspective for HCC therapy, but little is known about the mechanism of action of HIF-1 $\alpha$. A recent study demonstrated that metformin improves tumor oxygenation and radiotherapy outcomes [29]. Our data are consistent with this report and expand these findings by suggesting a mechanism by which metformin exerts its antitumor effect.

The currently proposed molecular mechanism for the anticancer action of metformin is primarily associated with inhibition of the mTOR pathway, dependent on or independent of AMPK activation. Significant inhibition of mTOR, and an increase in phosphorylated AMPK, was observed in pancreatic tissue of mice fed with metformin [30]. However, Memmott et al. demonstrated that metformin inhibited induction of the mTOR pathway in the absence of AMPK in mice lung cancer cells [31].
Sahra et al. similarly reported that metformin inhibited prostate cancer cell proliferation independent of AMPK activation [32]. Consistent with these observations, our present study showed that metformin inhibits hypoxiainduced HIF-1 $\alpha$ protein accumulation independent of AMPK activation.

Intracellular HIF-1 $\alpha$ protein content could be regulated at the level of protein translation or stability. In the present study, hypoxia-dependent HIF-1 $\alpha$ stabilization was observed in the presence of the proteasome inhibitor MG-132, which suppresses the degradation of HIF$1 \alpha$. In contrast, addition of cycloheximide to inhibit protein synthesis led to a much slower decline in HIF$1 \alpha$, indicating that metformin does not inhibit HIF-1 $\alpha$ synthesis but rather stimulates its degradation. The protein stability of HIF-1 $\alpha$ is modulated by environmental oxygen concentration or intracellular ROS level [33, 34]. Although previous studies showed that mitochondria-generated ROS promote protein stability of HIF-1 $\alpha[35,36]$, in our study the protein stability of HIF-1 $\alpha$ was not obviously changed by ROS, as measured by DHE staining. Interestingly, metformin efficiently reduces mitochondrial respiration, in accordance with a previous study showing that metformin impairs complex I of the respiratory chain leading to a marked decrease in respiration and tumorigenesis in colon cancer [37]. These data implied that a decrease in mitochondrial oxygen consumption of hepatoma cells in the presence of metformin involves the destabilization of hypoxia-induced HIF-1 $\alpha$.
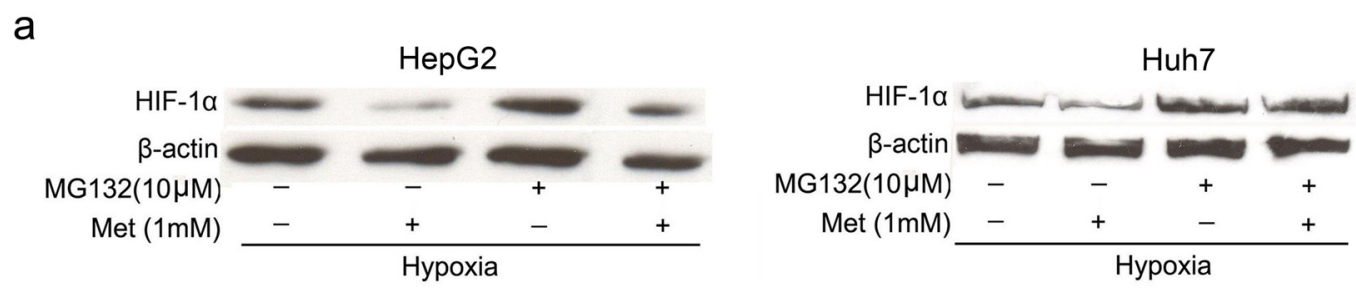

b
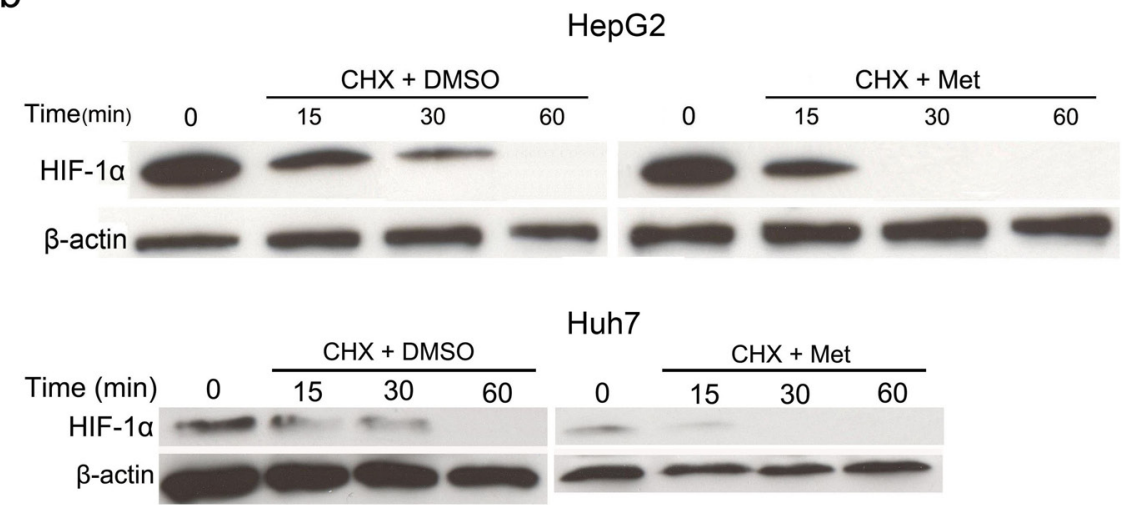

Figure 4: Effects of metformin on protein stability of HIF-1 $\boldsymbol{\alpha}$. a. The proteasomal inhibitor MG-132 (10 $\mu \mathrm{mol} / \mathrm{L})$ rescued the inhibitory effect of $1 \mathrm{mmol} / \mathrm{L}$ metformin on HIF-1 $\alpha$ protein accumulation in hypoxia. b. $\mathrm{HepG}_{2}$ and Huh7 cells were cultured in hypoxia for $4 \mathrm{~h}$, and then treated with $\mathrm{CHX}(4 \mu \mathrm{g} / \mathrm{ml}$; a translational inhibitor) and metformin for $0,15,30$, and 60 min in normoxia. The results indicated that metformin speeds up the degradation of HIF-1 $\alpha$ protein. 
a

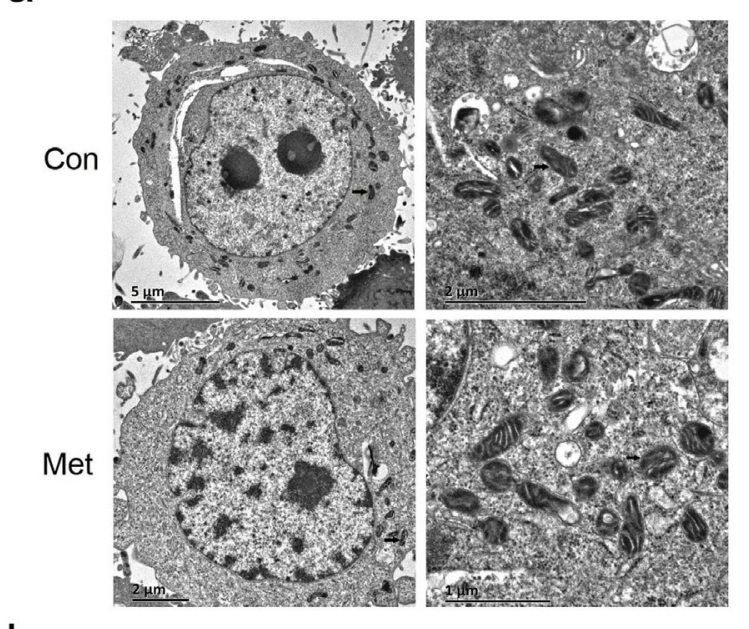

b

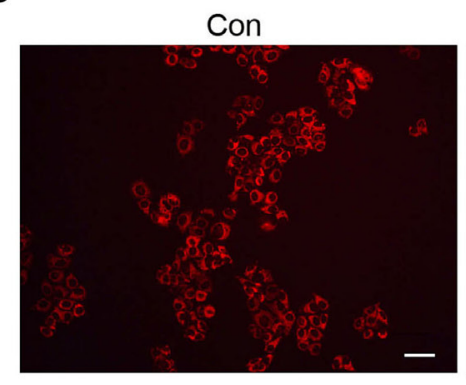

C

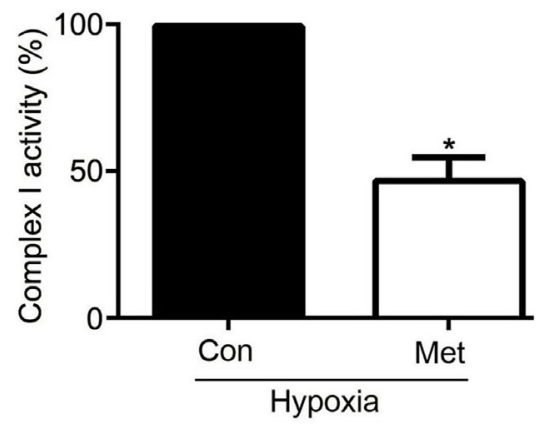

f d

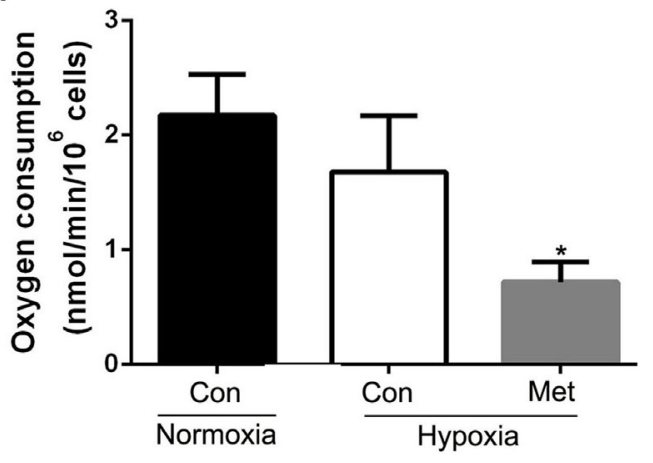

e
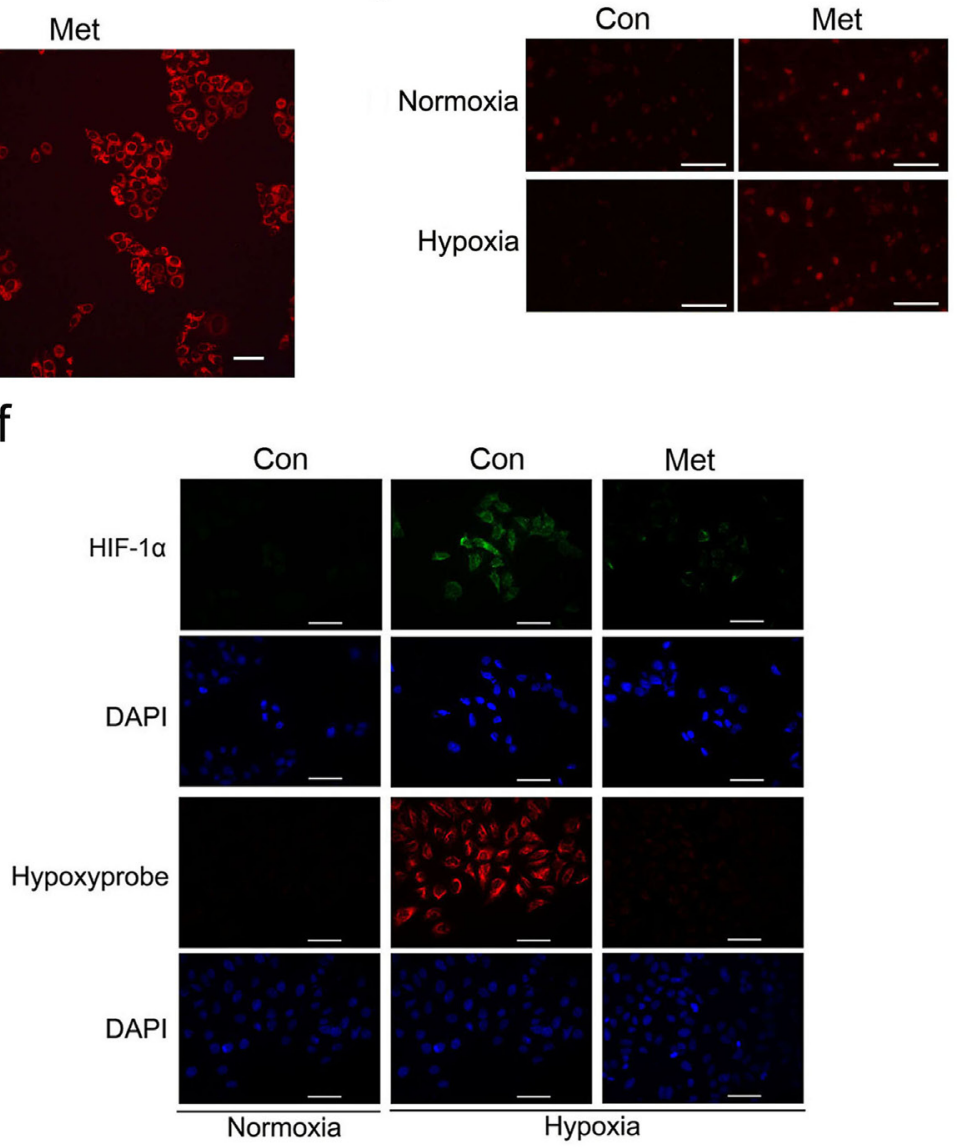

Figure 5: Effect of metformin on mitochondrial biogenesis and oxygen metabolism. a. Representative transmission electron microscopy images of mitochondria in $\mathrm{HepG}_{2}$ cells. b. Fluorescence microscopy analysis of mitochondrial mass in $\mathrm{HepG}_{2}$ cells after staining with mitotracker red. c. Changes in mitochondrial complex I activity in response to metformin treatment in hypoxia. The control value was set at $100 \%$. ${ }^{*} P<0.05$ versus the control. d. Metformin inhibited mitochondrial respiratory functions of $\mathrm{HepG}_{2}$ in normoxia and hypoxia. Cells were treated with $1 \mathrm{mmol} / \mathrm{L}$ metformin in normoxia or hypoxia for $4 \mathrm{~h}$ and then resuspended in normoxic medium. Oxygen consumption was measured in a sealed chamber using a Clark-type electrode. ${ }^{*} P<0.05$ compared with control in hypoxia. e. Effect of metformin on ROS production measured with DHE. $\mathrm{HepG}_{2}$ cells were treated with $1 \mathrm{mmol} / \mathrm{L}$ metformin for $4 \mathrm{~h}$ under normoxic or hypoxic conditions and then incubated with $2.5 \mu \mathrm{mol} / \mathrm{L} \mathrm{DHE}$ and viewed under a fluorescence microscope. f. Detection of hypoxic state and HIF-1 $\alpha$ expression in $\mathrm{HepG}_{2}$ cells by immunocytochemical analysis. Nuclei were stained with DAPI. Scale bars: $50 \mu \mathrm{m}$. All results are representative of three independent experiments. Values are given as the mean \pm SD. Con, control; Met, metformin. 
a

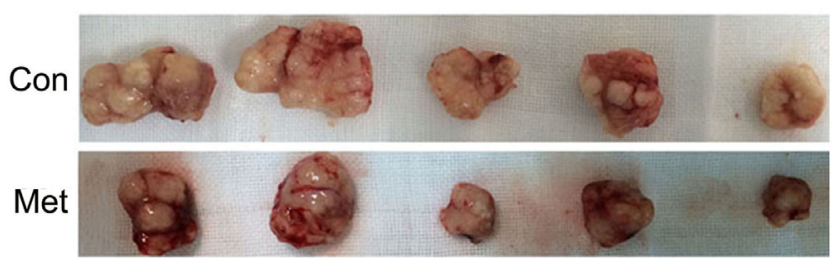

b

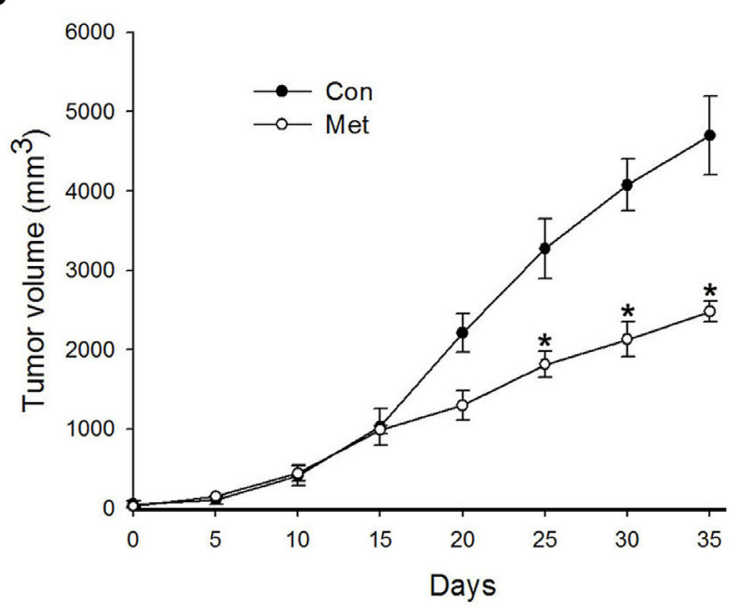

C

d
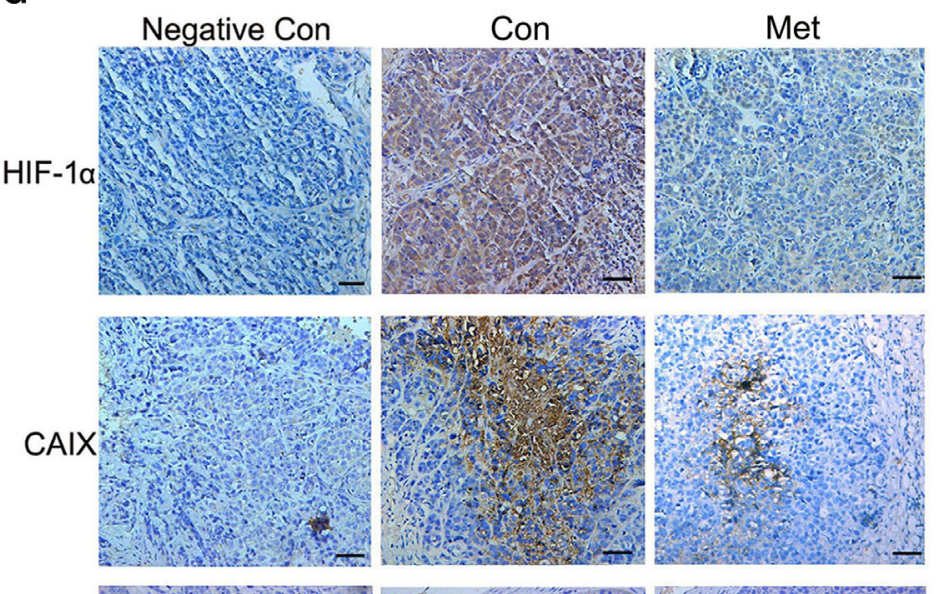

e
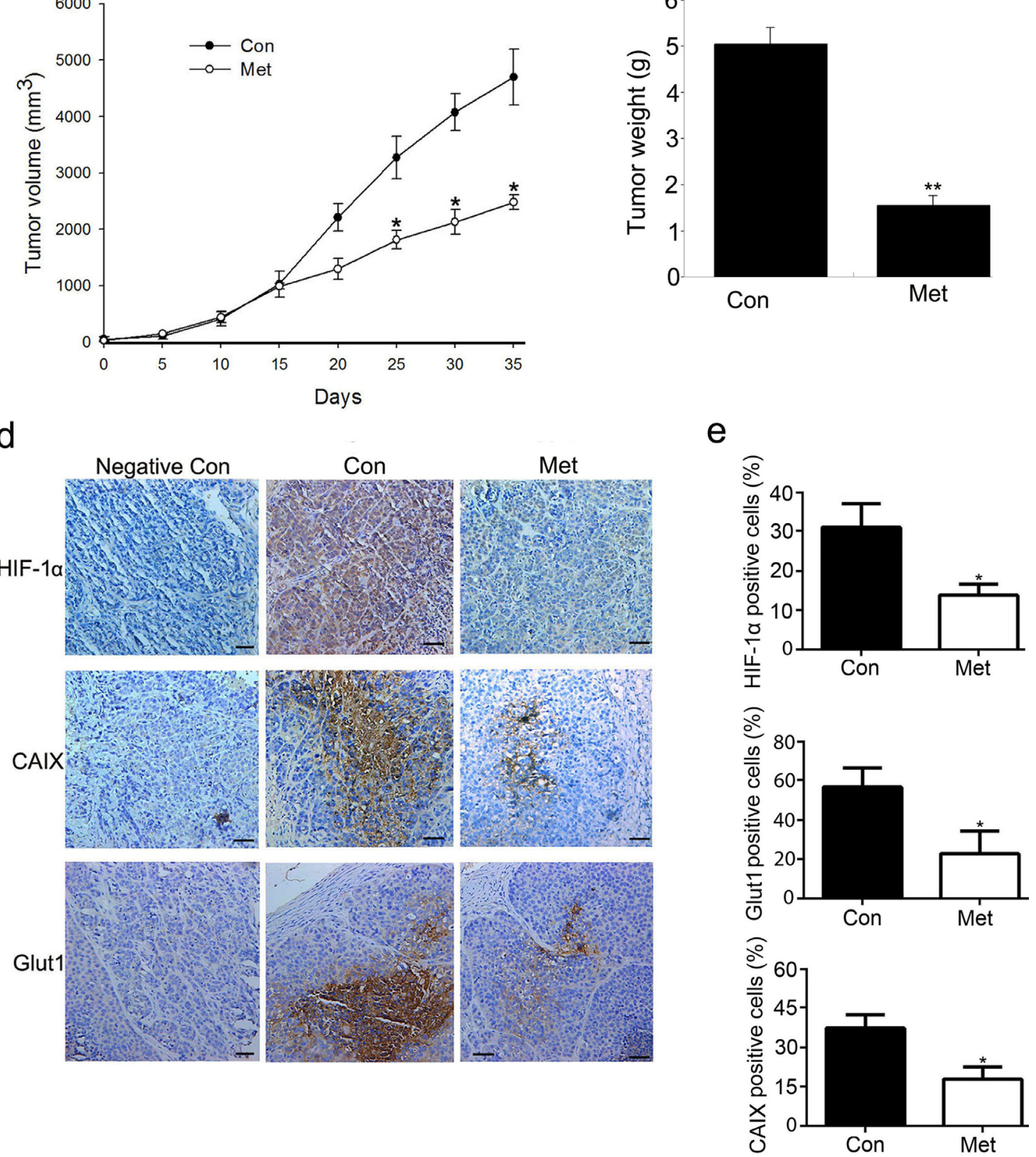

Figure 6: Metformin administration inhibits HCC xenograft tumor growth. a. Representative image of tumors dissected from vehicle-treated control mice and metformin-treated mice at $35 \mathrm{~d}$. b. Tumor growth in vehicle-treated control mice and metformin-treated mice. After tumor formation, mice were treated daily with intraperitoneal injection of metformin $(250 \mathrm{mg} / \mathrm{kg})$. c. Quantification of tumor weight 35 days post-tumor formation. Metformin significantly delayed tumor growth. d. Expression of HIF-1 $\alpha$, Glut1, and CAIX in tumor tissues was assessed by immunostaining and statistical graphs e. are shown. Scale bars: $50 \mu \mathrm{m}$. Data are represented as means \pm SD of each group. ${ }^{*} P<0.05,{ }^{* *} P<0.01$ compared with control. Con, control; Met, metformin. 
In summary, metformin facilitates protein degradation of HIF-1 $\alpha$ in HCC via suppression of mitochondrial oxygen consumption. These findings expand our understanding of the mechanism underlying the anticancer activity of metformin, and may help to optimize the treatment of $\mathrm{HCC}$.

\section{MATERIALS AND METHODS}

\section{Cell culture}

Two human hepatoma cell lines ( $\mathrm{HepG}_{2}$ and Huh7) obtained from the Cell Bank of Shanghai Institutes of Biological Sciences, Chinese Academy of Sciences were cultured in Dulbecco's modified Eagle medium (DMEM) supplemented with 10\% fetal bovine serum (Invitrogen, Carlsbad, CA, USA) and 1\% penicillin-streptomycin (Sigma, St Louis, MO, USA). Cell lines were maintained in a humidified atmosphere of $95 \%$ air and $5 \% \mathrm{CO}_{2}$ at $37^{\circ} \mathrm{C}$. Hypoxic culture conditions were achieved with a hypoxia incubator containing a gas mixture of $94 \% \mathrm{~N}_{2}$, $5 \% \mathrm{CO}_{2}$, and $1 \% \mathrm{O}_{2}$.

\section{Reagents and antibodies}

Metformin (1,1 dimethylbiguanide-hydrochloride), dimethyl sulfoxide (DMSO), MG132, cobalt chloride $\left(\mathrm{CoCl}_{2}\right)$, Compound $\mathrm{C}(\mathrm{CC})$, cycloheximide $(\mathrm{CHX})$ and oxidative fluorescent dihydroethidium (DHE) were obtained from Sigma-Aldrich. A pimonidazole hydrochloride kit was purchased from Hypoxyprobe Inc. (Burlington, MA, USA). The primary antibodies against AMPK $\alpha$, phospho-AMPK(Thr172), CAIX, Glut1, Ki67 and $\beta$-actin were obtained from Cell Signaling Technology (Beverly, MA, USA), and HIF-1 $\alpha$ antibody was from Abcam Company (Cambridge, MA, USA).

\section{Western blotting}

Aliquots of cell lysate containing 30-50 $\mu \mathrm{g}$ of protein from cells incubated under normoxic or hypoxic conditions were resolved by $10 \%$ SDS-PAGE and electrophoretically transferred onto PVDF membranes (Millipore Corporation, Billerica, MA, USA) in a transfer buffer. The membrane was washed and incubated with specific primary antibodies of interest followed by appropriate secondary antibodies, and visualized with enhanced chemiluminescence reagent (Thermo Scientific, Rockford, IL, USA).

\section{Quantitative real-time RT-PCR}

Total RNA extraction was conducted using Trizol reagent (Invitrogen). First-strand cDNA synthesis was performed using a RevertAid First Strand cDNA synthesis kit (Thermo Scientific, MA, USA) following the manufacturer's protocol. Each cDNA sample was analyzed for gene expression by quantitative real-time PCR with an
ABI 7500 Sequence Detector (Applied Biosystems, Foster City, CA, USA) using the SYBR Green Universal PCR Master Mix (Applied Biosystems). Specific primers for HIF-1 $\alpha$ (forward 5'-AGTGTACCCTAACTAGCCG-3', reverse 5'- CACAAATCAGCACCAAGC-3'), CAIX (forward 5'-TGTGCTCCTGGTTCTGTTCT-3', reverse 5'-GCTCCTCGGGTGTCTTGT-3'), Glut1 (forward 5'-CGCCTTTGCCAGAGTTGA-3', reverse 5'-TTCTTCCAAGCGAGACAGC-3'), and $\beta$-actin (forward 5'-GGCATGGGTCAGAAGGATT-3', reverse 5'-CTTCTACAATGAGCTGCGTGTG-3') were used in this study. The PCR reaction was performed at $95^{\circ} \mathrm{C}$ for $30 \mathrm{~s}$, followed by 40 cycles at $95^{\circ} \mathrm{C}$ for $5 \mathrm{~s}$ and $58^{\circ} \mathrm{C}$ for $30 \mathrm{~s}$. For each sample, the relative quantity of product was calculated using the $2^{-\Delta \Delta C(\mathrm{~T})}$ method.

\section{Oxygen consumption measurements}

Cells were incubated under normoxic $\left(21 \% \mathrm{O}_{2}\right)$ or hypoxic $\left(1 \% \mathrm{O}_{2}\right)$ conditions and then treated with or without drugs for $4 \mathrm{~h}$. The average intracellular oxygen consumption rate was measured in a sealed chamber using a Clark-type electrode according to the manufacturer's instructions.

\section{Transfection with siRNA}

Silencing of $A M P K \alpha 1$ gene expression was achieved by the siRNA strategy as described previously [38]. At 48 $\mathrm{h}$ after transfection, $\mathrm{HepG}_{2}$ and Huh7 cells were treated with $1 \mathrm{mmol} / \mathrm{L}$ metformin and subsequently incubated in hypoxia for $4 \mathrm{~h}$. Protein levels were detected by western blot analysis.

\section{Luciferase assay}

Cells $\left(2 \times 10^{5}\right)$ were seeded in a 6-well plate and incubated overnight. Cells were transfected with $0.5 \mu \mathrm{g}$ HIF-1 $\alpha$ luciferase reporter vector designed to measure intracellular HIF-1 $\alpha$ (Panomics, CA, USA) and 0.5 $\mu \mathrm{g}$ p-EGFP-C2 using lipofectamine 2000 (Invitrogen) according to the manufacturer's protocol. At $24 \mathrm{~h}$ after co-transfection, cells were treated with metformin and incubated under hypoxia for $12 \mathrm{~h}$. Luciferase was measured using the luciferase assay system (Promega, Madison, MI, USA). pEGFP-C2 vector was used for normalization of transfection efficiency, and relative luciferase activity (defined as reporter activity) was calculated as the ratio of luciferase/EGFP activity.

\section{Determination of mitochondrial complex I activity}

Complex I activity was determined using the Dipstick Assay kit (MitoSciences, Eugene, OR, USA) according to the manufacturer's protocols, as previously described [26]. 


\section{Imaging of reactive oxygen species}

Dihydroethidium (DHE) was used to evaluate the intracellular production of superoxide. Briefly, $\mathrm{HepG}_{2}$ cells were cultured in the presence or absence of $1 \mathrm{mmol} / \mathrm{L}$ metformin for $4 \mathrm{~h}$ under normoxic and hypoxic conditions, washed with DMEM lacking serum and phenol red, and incubated with $2.5 \mu \mathrm{mol} / \mathrm{L}$ DHE. After incubation for 30 min in the dark, the cells were washed with cold PBS and examined by fluorescence microscopy.

\section{Detection of cellular hypoxia}

Cellular hypoxia was detected by addition of pimonidazole hydrochloride, a marker of hypoxia that binds to cells according to oxygen pressure $\left(\mathrm{pO}_{2}\right)$ levels. $\mathrm{HepG}_{2}$ cells treated with $1 \mathrm{mmol} / \mathrm{L}$ metformin were exposed to hypoxia for $4 \mathrm{~h}$ and then subjected to pimonidazole staining according to the manufacturer's instructions.

\section{In vivo study}

All animal procedures were approved by the Animal Experimentation Ethics Committee of Guangzhou Medical University. Male nude mice (BALB/c, 4-6 weeks old) were purchased from the Laboratory Animal Services Center of Guangdong Province. To obtain HCC xenografts, $5 \times 10^{6}$ cells were injected subcutaneously into the right flank of each mouse. At 12 days after cell implantation, the mice were randomly divided into groups (six mice/group). Mice in the experimental group were intraperitoneally injected with metformin at a dose of $250 \mathrm{mg} / \mathrm{kg}$ body weight per day whereas the control group received an equal volume of normal saline. Tumor volume was calculated every 5 days using the equation: $\left[\right.$ length $\times(\text { width })^{2} / 2$ ]. The mice were sacrificed after 35 days and the tumors were weighed and then fixed in $10 \%$ formalin for immunohistochemical staining.

\section{Immunohistochemistry}

Paraffin-embedded, formalin-fixed tissues were immunostained for HIF-1 $\alpha$, CAIX, and Glut 1 protein using standard immunohistochemistry procedures according to the manufacturers' instruction. Immunostained slides were evaluated independently by two pathologists in a doubleblind manner. Negative controls were prepared in the same way but without primary antibodies.

\section{Statistical analyses}

The SPSS 16.0 and Sigmaplot 10.0 programs were used for general statistical analysis. Experimental data were expressed as the mean $\pm \mathrm{SD}$. Differences between groups were assessed by Student $t$ test for comparison of only two groups, or using one-way analysis of variance (ANOVA) for more than two groups. All tests performed were two-tailed. $P<0.05$ was considered statistically significant.

\section{ACKNOWLEDGMENTS}

This work was supported by grants from the National Natural Science Foundation of China (No. 81402011), Department of Science and Technology of Guangdong Province (No. 2013B021800178), Pearl River S\&T Nova Program of Guangzhou (No. 2012J2200032), Department of Education of Guangdong Province (No. 2015001), and Outstanding Young Teachers of Guangdong Province (No. B158030).

\section{CONFLICTS OF INTEREST}

The authors declare no conflict of interest.

\section{REFERENCES}

1. Wilson GK, Tennant DA and McKeating JA. Hypoxia inducible factors in liver disease and hepatocellular carcinoma: current understanding and future directions. J Hepatol. 2014; 61:1397-1406.

2. Wilson WR and Hay MP. Targeting hypoxia in cancer therapy. Nat Rev Cancer. 2011; 11:393-410.

3. Lu X and Kang Y. Hypoxia and hypoxia-inducible factors: master regulators of metastasis. Clin Cancer Res. 2010; 16:5928-5935.

4. Liu L, Zhu XD, Wang WQ, Shen Y, Qin Y, Ren ZG, Sun $\mathrm{HC}$ and Tang ZY. Activation of beta-catenin by hypoxia in hepatocellular carcinoma contributes to enhanced metastatic potential and poor prognosis. Clin Cancer Res. 2010; $16: 2740-2750$.

5. Semenza GL. Regulation of oxygen homeostasis by hypoxia-inducible factor 1. Physiology (Bethesda). 2009; 24:97-106.

6. Amann T, Maegdefrau U, Hartmann A, Agaimy A, Marienhagen J, Weiss TS, Stoeltzing O, Warnecke C, Scholmerich J, Oefner PJ, Kreutz M, Bosserhoff AK and Bosserhoff AK. GLUT1 expression is increased in hepatocellular carcinoma and promotes tumorigenesis. Am J Pathol. 2009; 174:1544-1552.

7. McIntyre A, Patiar S, Wigfield S, Li JL, Ledaki I, Turley H, Leek R, Snell C, Gatter K, Sly WS, Vaughan-Jones RD, Swietach P and Harris AL. Carbonic anhydrase IX promotes tumor growth and necrosis in vivo and inhibition enhances anti-VEGF therapy. Clin Cancer Res. 2012; 18:3100-3111.

8. McDonald PC, Winum JY, Supuran CT and Dedhar S. Recent developments in targeting carbonic anhydrase IX for cancer therapeutics. Oncotarget. 2012; 3:84-97.

9. Kasznicki J, Sliwinska A and Drzewoski J. Metformin in cancer prevention and therapy. Ann Transl Med. 2014; 2:57. 
10. Bailey CJ and Turner RC. Metformin. N Engl J Med. 1996; 334:574-579.

11. Evans JM, Donnelly LA, Emslie-Smith AM, Alessi DR and Morris AD. Metformin and reduced risk of cancer in diabetic patients. BMJ. 2005; 330:1304-1305.

12. Chlebowski RT, McTiernan A, Wactawski-Wende J, Manson JE, Aragaki AK, Rohan T, Ipp E, Kaklamani VG, Vitolins M, Wallace R, Gunter M, Phillips LS, Strickler H, et al. Diabetes, metformin, and breast cancer in postmenopausal women. J Clin Oncol. 2012; 30:2844-2852.

13. Sesen J, Dahan P, Scotland SJ, Saland E, Dang VT, Lemarie A, Tyler BM, Brem H, Toulas C, Cohen-Jonathan Moyal E, Sarry JE and Skuli N. Metformin inhibits growth of human glioblastoma cells and enhances therapeutic response. PLoS One. 2015; 10:e123721.

14. Zhao D, Long XD, Lu TF, Wang T, Zhang WW, Liu YX, Cui XL, Dai HJ, Xue F and Xia Q. Metformin decreases IL-22 secretion to suppress tumor growth in an orthotopic mouse model of hepatocellular carcinoma. Int J Cancer. 2015; 136:2556-2565.

15. Li J, Hernanda PY, Bramer WM, Peppelenbosch MP, van Luijk J and Pan Q. Anti-Tumor Effects of Metformin in Animal Models of Hepatocellular Carcinoma: A Systematic Review and Meta-Analysis. PLoS One. 2015;10:e0127967.

16. Ece H, Cigdem E, Yuksel K, Ahmet D, Hakan E and Oktay TM. Use of oral antidiabetic drugs (metformin and pioglitazone) in diabetic patients with breast cancer: how does it effect serum Hif-1 alpha and 8Ohdg levels? Asian Pac J Cancer Prev. 2012;13:5143-5148.

17. Ling S, Tian Y, Zhang H, Jia K, Feng T, Sun D, Gao Z, Xu F, Hou Z, Li Y and Wang L.Metformin reverses multidrug resistance in human hepatocellular carcinoma Bel-7402/ 5-fluorouracil cells. Mol Med Rep. 2014;10:2891-29897.

18. Viollet B and Andreelli F. AMP-activated protein kinase and metabolic control. Handb Exp Pharmacol. 2011; 203:303-330.

19. Shaw RJ, Lamia KA, Vasquez D, Koo SH, Bardeesy N, Depinho RA, Montminy M and Cantley LC. The kinase LKB1 mediates glucose homeostasis in liver and therapeutic effects of metformin. Science. 2005; 310:1642-1646.

20. Algire C, Amrein L, Bazile M, David S, Zakikhani M and Pollak M. Diet and tumor LKB1 expression interact to determine sensitivity to anti-neoplastic effects of metformin in vivo. Oncogene. 2011; 30:1174-1182.

21. Shackelford DB, Vasquez DS, Corbeil J, Wu S, Leblanc M, Wu CL, Vera DR and Shaw RJ. mTOR and HIF-1alphamediated tumor metabolism in an LKB1 mouse model of Peutz-Jeghers syndrome. Proc Natl Acad Sci USA. 2009; 106:11137-11142.

22. Li W, Saud SM, Young MR, Chen G and Hua B. Targeting AMPK for cancer prevention and treatment. Oncotarget. 2015; 6:7365-7378.

23. Han G, Gong H, Wang Y, Guo S and Liu K. AMPK/ mTOR-mediated inhibition of survivin partly contributes to metformin-induced apoptosis in human gastric cancer cell. Cancer Biol Ther. 2015; 16: 77-87.

24. Semenza GL. Targeting HIF-1 for cancer therapy. Nat Rev Cancer. 2003; 3:721-732.

25. Wang GL and Semenza GL. Purification and characterization of hypoxia-inducible factor 1. J Biol Chem. 1995; 270:1230-1237.

26. Liu J, Hou M, Yuan T, Yi G, Zhang S, Shao X, Chen J, Jia $\mathrm{X}$ and He Z. Enhanced cytotoxic effect of low doses of metformin combined with ionizing radiation on hepatoma cells via ATP deprivation and inhibition of DNA repair. Oncol Rep. 2012; 28:1406-1412.

27. Papandreou I, Cairns RA, Fontana L, Lim AL and Denko NC. HIF-1 mediates adaptation to hypoxia by actively downregulating mitochondrial oxygen consumption. Cell Metab. 2006; 3:187-197.

28. Anedda A, Rial E and Gonzalez-Barroso MM. Metformin induces oxidative stress in white adipocytes and raises uncoupling protein 2 levels. J Endocrinol. 2008; 199:33-40.

29. Zannella VE, Dal Pra A, Muaddi H, McKee TD, Stapleton S, Sykes J, Glicksman R, Chaib S, Zamiara P, Milosevic M, Wouters BG, Bristow RG and Koritzinsky M. Reprogramming metabolism with metformin improves tumor oxygenation and radiotherapy response. Clin Cancer Res. 2013; 19: 6741-6750.

30. Mohammed A, Janakiram NB, Brewer M, Ritchie RL, Marya A, Lightfoot S, Steele VE and Rao CV. Antidiabetic Drug Metformin Prevents Progression of Pancreatic Cancer by Targeting in Part Cancer Stem Cells and mTOR Signaling. Transl Oncol. 2013; 6:649-659.

31. Memmott RM, Mercado JR, Maier CR, Kawabata S, Fox $\mathrm{SD}$ and Dennis PA. Metformin prevents tobacco carcinogen-induced lung tumorigenesis. Cancer Prev Res (Phila). 2010; 3:1066-1076.

32. Ben Sahra I, Regazzetti C, Robert G, Laurent K, Le Marchand-Brustel Y, Auberger P, Tanti JF, GiorgettiPeraldi S and Bost F. Metformin, independent of AMPK, induces mTOR inhibition and cell-cycle arrest through REDD1. Cancer Res. 2011; 71:4366-4372.

33. Wilson WR and Hay MP. Targeting hypoxia in cancer therapy. Nat Rev Cancer. 2011; 11:393-410.

34. Robertson ED, Semenchenko K, and Wasylyk B. Crosstalk between Mdm2, p53 and HIF1-alpha: distinct responses to oxygen stress and implications for tumour hypoxia. Subcell Biochem. 2014; 85:199-214.

35. Foretz M, Guigas B, Bertrand L, Pollak M and Viollet B. Metformin: from mechanisms of action to therapies. Cell Metab. 2014; 20:953-966.

36. Mansfield KD, Guzy RD, Pan Y, Young RM, Cash TP, Schumacker PT and Simon MC. Mitochondrial dysfunction resulting from loss of cytochrome $\mathrm{c}$ impairs cellular oxygen sensing and hypoxic HIF-alpha activation. Cell Metab. 2005;1:393-399. 
37. Zhang Y, Guan M, Zheng Z, Zhang Q, Gao F and Xue Y. Effects of metformin on CD133+ colorectal cancer cells in diabetic patients. PLoS One. 2013; 8:e81264.

38. Yi G, He Z, Zhou X, Xian L, Xian L, Yuan T, Jia X, Hong J, He L and Liu J. Low concentration of metformin induces a p53-dependent senescence in hepatoma cells via activation of the AMPK pathway. Int J Oncol. 2013; 43:1503-1510. 